\title{
Comparative study of intravenous ondansetron and intrathecal fentanyl for prevention of perioperative nausea and vomiting during caesarean delivery under spinal anaesthesia with hyperbaric bupivacaine.
} Authors: -

\author{
1. Dr. Kasomhung Soreingam \\ Assistant Professor, Department of Anaesthesiology, JNIMS, Imphal, email ksoreingam@gmail.com \\ 2. Dr. Takhelmayum Hemjit Singh \\ Assistant Professor, Department of Anaesthesiology, RIMS, Imphal, email takhelhem@yahoo.com \\ 3. Dr. Rupendra Singh Thokchom \\ Associate Professor, Department of Anaesthesiology, RIMS, Imphal, email takhelhem@yahoo.com \\ 4. Dr. Yumnam Arun Kumar Singh \\ Assistant Professor, Department of Anaesthesiology, RIMS, Imphal, email takhelhem@yahoo.com \\ 5. Dr. Ashem Jack Meitei \\ Assistant Professor, Department of Anaesthesiology, RIMS, Imphal, email takhelhem@yahoo.com \\ 6. Dr. Sanasam Sarat Singh \\ Professor, Department of Anaesthesiology, RIMS, Imphal, email takhelhem@yahoo.com
}

\author{
Research conducted at the Department of Anaesthesiology, RIMS, Imphal \\ Total no of pages- 7 \\ Total no of Tables- 1 \\ Total no of figure- 2 \\ Conflict of interest- Nil \\ Funding- Nil
}

Address for correspondence \& Reprint: - Dr. Takhelmayum Hemjit Singh

Assistant Professor, Department of Anaesthesiology, RIMS, Imphal, email takhelhem@yahoo.com,

PIN-795001, Mobile-9436021445

\begin{abstract}
:
Objectives: Some earlier studies has highlighted the analgesic potentiating effects of intrathecal fentanyl hydrochloride while some recent studies have focused on the effects of decreasing post operative nausea and vomiting. Hence, the current study was planned on comparing the effects of intrathecal fentanyl and intravenous ondansetron in reducing the perioperative nausea and vomiting.

Materials and methods: In this randomized prospective study, 140 patients (ASA I\&II, aged 18-35 years ) undergoing elective caesarean section were divided into two equal groups $(\mathrm{n}=70)$ to receive either intrathecal 20 microgram $(0.4 \mathrm{ml})$ with $2.2 \mathrm{ml}$ bupivacaine $0.5 \%$ heavy plus $2 \mathrm{ml}$ normal saline intravenously (Group F) or $0.4 \mathrm{ml}$ of normal saline with equal amount of bupivacaine $0.5 \%$ heavy plus $4 \mathrm{mg}(2 \mathrm{ml})$ of ondansetron intravenously (Group O) to compare their effects on perioperative nausea and vomiting .

Results: The incidences of intraoperative nausea (12.8\% vs $7.15 \%)$, vomiting (8.58\% vs $4.28 \%$ ) and retching $(8.58 \%$ vs $4.28 \%$ ) were higher in the ondansetron group compared with the fentanyl group and statistically not significant(nausea , $\mathrm{P}=0.26$; vomiting, $\mathrm{P}=0.30$ and retching, $\mathrm{P}=0.30$ ). However, the incidence of postoperative nausea, vomiting and retching were higher in the fentanyl group $(7.15 \%$ vs $2.86 \%, \mathrm{P}=0.25 ; 4.28 \mathrm{vs} 2.86, \mathrm{P}=0.65$ and $4.28 \mathrm{vs} 2.86, \mathrm{P}=0.65)$ respectively. Intraoperative and postoperative hemodynamic parameters were comparable in the two groups $(\mathrm{P}>0.05)$.

Conclusion: Although not statistically significant, the incidences of nausea, vomiting and retching were higher in the ondansetron group intraopertively and the same being higher in the fentanyl group postopertively.
\end{abstract}

Key-words: intravenous ondansetron, intrathecal fentanyl, PONV, caesarean delivery, spinal anaesthesia.

\section{Introduction}

Spinal anaesthesia is the most popular and common technique used for caesarean section at present because it is easier to perform, and has rapid and predictable onset of action. Nausea and vomiting is one of the commonest unpleasant complication occurring both intra and postoperatively with an incidence of 50-80\% when no prophylaxis was given in both regional and general anaesthesia. ${ }^{[1]}$ Several techniques like pharmacological and non-pharmacological have proved to diminish this problem but no single intervention is known so far to eliminate it completely. Even though anti-emetic drugs reduced the incidences of nausea and vomiting, it has got its own undesirable side effects; metoclopramide has rare association like dystonia reaction, droperidol may cause extra pyramidal symptom and dysphoria ${ }^{[2]}$ and may induce 
tachycardia. ${ }^{[3]}$ 5HT3 antagonist like ondansetron, granisetron, palonosetron are all effective in reducing post-operative nausea and vomiting, ${ }^{[4,5]}$ with low incidences of side-effects but high acquisition cost.

Some earlier studies have highlighted the well known analgesic properties of fentanyl but some recent studies have focus on the effect of decreasing the post-operative nausea and vomiting. Recently intrathecal administration of lipophilic opioid such as fentanyl ${ }^{[6,7,8,9]}$ and benzodiazepine like midazolam ${ }^{[10,11]}$ has been reported to minimize the incidence of intra-operative and early post-operative nausea and vomiting in caesarean section under spinal anaesthesia. Neither of the two pharmacological agents have been known to possess anti-emetic properties in their own rights, they probably reduce it by improving the quality of and duration of pain relief along with $0.5 \%$ of hyperbaric bupivacaine. ${ }^{[6]}$

As a continuation of the ever going search for better and more effective drug among the anti-emetic agents commonly used in practice, a comparative study of intravenous ondansetron $(4 \mathrm{mg})$ and intrathecal fentanyl $(20 \mu \mathrm{g})$ was carried out to ameliorate perioperative nausea and vomiting.

\section{Methods}

The study was a prospective, randomized, double-blinded one, conducted in the department of Anaesthesiology, in a tertiary care centre, Imphal, Manipur, after getting approval from the Institutional ethical committee and written informed consent of 140 term parturient (ASA Grade I and II) who opted for elective caesarean section under spinal anaesthesia. They were divided into two equal group (group-F and group- $\mathrm{O}$ ) of 70 patients each after computer generated randomization. Group-F were to received intrathecal (IT) $12 \mathrm{mg}$ of $0.5 \%$ hyperbaric bupivacaine with fentanyl-20 $\mu \mathrm{g}(0.4 \mathrm{ml})$ and $2 \mathrm{ml}$ of intravenous normal saline (IV. NS) and group-O were to received intrathecal $12 \mathrm{mg}$ of $0.5 \%$ hyperbaric bupivacaine with $0.4 \mathrm{ml}$ of normal saline and intravenous (IV) ondansetron $4 \mathrm{mg}(2 \mathrm{ml})$ after spinal anaesthesia.

Patients with the history of motion sickness, hyperemesis gravidarum, allergy to certain drugs and contraindication to spinal anaesthesia were excluded from the study. After proper pre-operative assessment, the patient was preloaded with $1000 \mathrm{ml}$ of Ringer's lactate over 30 minutes and no other premedication were given. Multi parameter Monitors were connected and baseline reading of pulse rate, blood pressure, arterial oxygen saturation (SPO2), respiratory rate and foetal heart rate were noted.

Under strict aseptic and antiseptic precaution, using 25 gauze quincke spinal needle, the study drug with hyperbaric bubivacaine was injected intrathecally in left lateral position, then the patient was turned on the back immediately, in supine position.

All the patients were assessed for the level of block, nausea, vomiting, duration of effective analgesia, respiratory depression and other side effect like shivering and pruritus intraoperatively. Nausea, vomiting and retching were recorded with subjective complain of 'Yes' or 'No' variable. Also after the block, patient were monitored for pulse rate and blood pressure every $2 \mathrm{~min}$ for first $10 \mathrm{~min}$, every $5 \mathrm{~min}$ up to $40 \mathrm{~min}$ and every $10 \mathrm{~min}$ thereafter till the sensory block regresses to L1. Vomiting and retching in either study group were treated with $4 \mathrm{mg}$ IV rescue ondansetron and inj. fentanyl $50 \mu \mathrm{g}$ iv was given as rescue analgesic.

APGAR score at 1 and 5 min was noted for the baby. Bradycardia i.e $<60$ beats per minute was treated with injection atropine $0.6 \mathrm{mg}$ intravenously. Hypotension i.e $<20 \%$ below the baseline systolic blood pressure was corrected with rapid infusion of IV fluids and rescue injection mephentermine $6 \mathrm{mg}$ IV.

At the end of the procedure, all the patients were to receive $75 \mathrm{mg}$ Diclofenac Sodium IM, which were repeated every 12 hourly for $24 \mathrm{hr}$ post-operatively. The patients were monitored in the post-anaesthesia care unit and rescue inj. fentanyl $50 \mu \mathrm{g}$ iv was given when the patient demanded.

Sample size was calculated based on the study conducted by Manullang TR et al ${ }^{[6]}$ on the comparison of IT fentanyl and IV ondansetron for prevention of PONV during LSCS and with the assumption of $\alpha=0.05 \& \beta=0.8$. Continous variable were analysed with student ' $t$ ' test, categorical data with Chi-square test, etc whichever were appropriate. The datas collected were entered on a computer and analysed with Statistical Package of Social Sciences (SPSS Inc. version 20, Chicago, IL, USA).

\section{Results}

There was no significant difference in patients' demographic mean variables of age and weight in the two groups(Group F Vs Group O) as 27.64 \pm 4.45 years vs $26.71 \pm 4.45$ years and $59.36 \pm 7.84 \mathrm{~kg}$ vs $57.50 \pm 6.05 \mathrm{~kg}$, (P>0.05). No significant differences in the heart rate and blood pressure were also observed between the groups at different time intervals. (As shown in Fig 1\&2) The incidences of intraoperative nausea (12.8\% vs $7.15 \%, \mathrm{P}=0.26)$, vomiting $8.58 \%$ vs $4.28 \%$, $\mathrm{P}=0.30)$ and retching $(8.58 \%$ vs $4.28 \%, \mathrm{P}=0.30)$ were higher in the ondansetron group compared with the fentanyl group . However, the incidence of postoperative nausea, vomiting and retching were higher in the Fentanyl group (7.15\% vs $2.86 \%, \mathrm{P}=0.25 ; 4.28 \mathrm{vs} 2.86, \mathrm{P}=0.65$ and $4.28 \mathrm{vs} 2.86, \mathrm{P}=0.65$ ) respectively and statistically not significant. (TABLE 1 ) 
Comparative Study Of Intravenous Ondansetron And Intrathecal Fentanyl For Preventi...

Figure -1 showing the distribution mean of mean arterial blood pressure(in $\mathrm{mm} \mathrm{Hg}$ ) of the two groups at different time points.

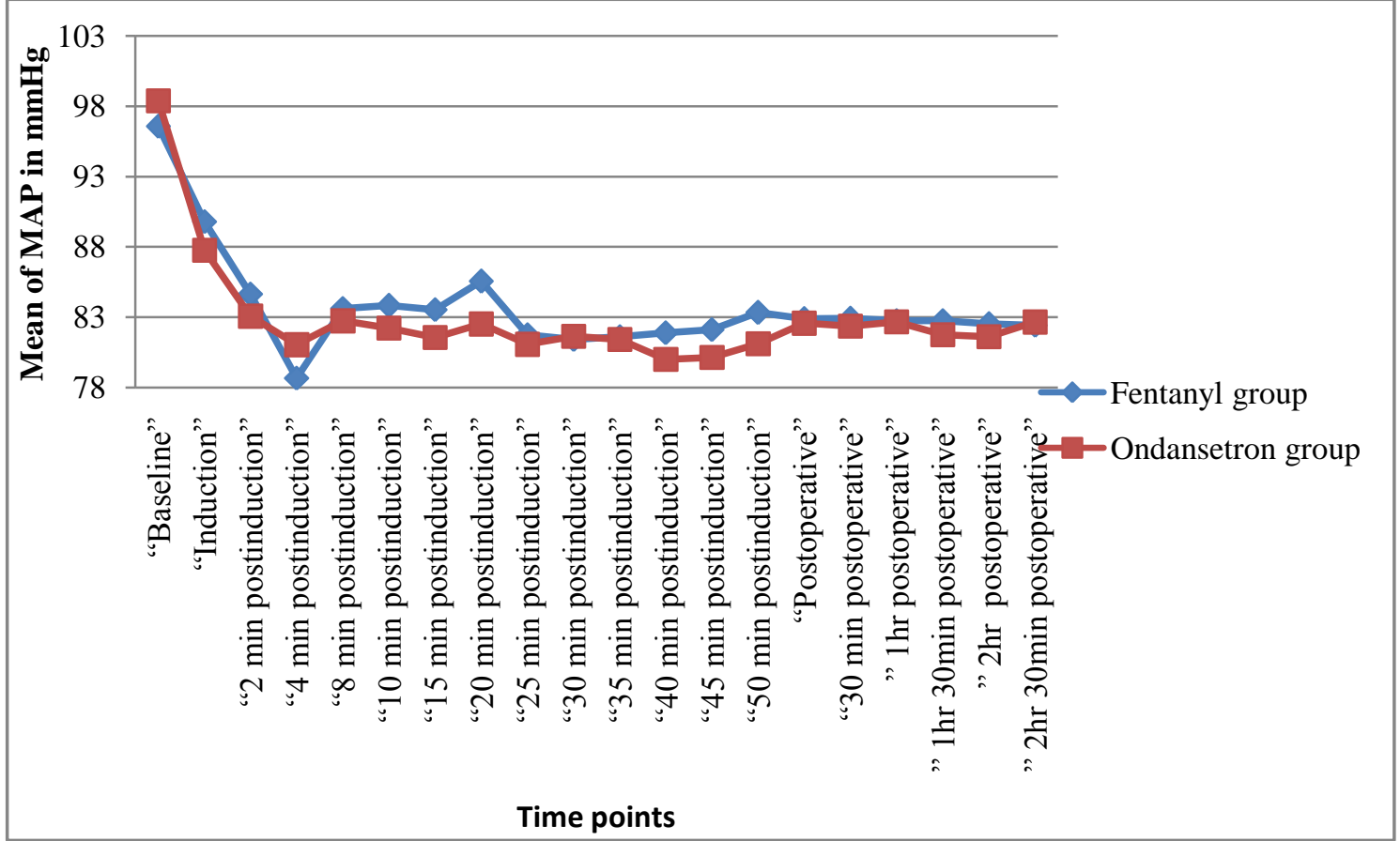

Figure -2, showing the distribution of mean heart rate (per second) of the two groups at different time points

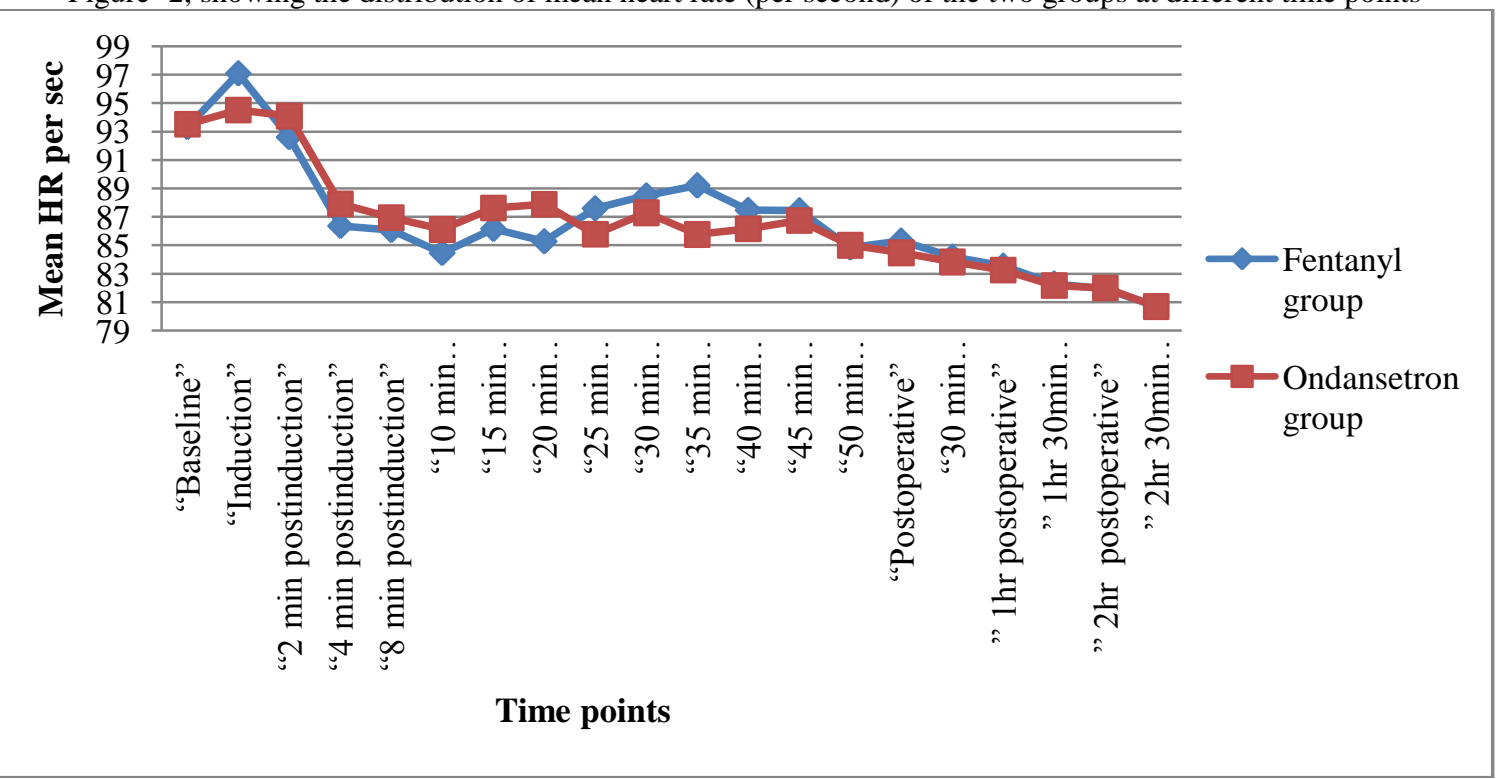

Table1 showing the distribution and comparison of intraoperative and postoperative side effects in the two groups.

\begin{tabular}{|c|c|c|c|c|c|}
\hline Time points & Side effects & $\begin{array}{l}\text { Group fentanyl }(F) \\
\quad n=70 \\
(\text { Mean } \pm S D)\end{array}$ & $\begin{array}{c}\text { Group } \\
\text { ondansetron }(O) \\
n=70 \\
(\text { Mean } \pm S D)\end{array}$ & $\begin{array}{l}\text { Statistical test } \\
\text { value/Chi- } \\
\text { square }\left(\chi^{2}\right) \text { test }\end{array}$ & $\begin{array}{l}\text { P value \& } \\
\text { inference }\end{array}$ \\
\hline \multirow{4}{*}{$\begin{array}{l}\text { INTRA- } \\
\text { OPERATIVE }\end{array}$} & Vomiting & $\begin{array}{l}\text { Yes }=3(4.28 \%) \\
\text { No }=67(95.72 \%)\end{array}$ & $\begin{array}{l}\text { Yes }=6(8.58 \%) \\
\text { No }=64(91.42 \%)\end{array}$ & 1.07 & $0.30(\mathrm{NS})$ \\
\hline & Nausea & $\begin{array}{l}\text { Yes }=5(7.15 \%) \\
\text { No }=65(92.85 \%\end{array}$ & $\begin{array}{l}\text { Yes }=9(12.87 \%) \\
\text { No }=61(87.13 \%)\end{array}$ & 1.27 & $0.26(\mathrm{NS})$ \\
\hline & Retching & $\begin{array}{l}\text { Yes }=3(4.28 \%) \\
\text { No }=67(95.72 \%)\end{array}$ & $\begin{array}{l}\text { Yes }=6(8.58 \%) \\
\text { No }=64(91.42 \%)\end{array}$ & 1.07 & $0.30(\mathrm{NS})$ \\
\hline & Vomiting & Yes $=3(4.28 \%)$ & Yes $=2(2.86 \%)$ & 0.21 & $0.65(\mathrm{NS})$ \\
\hline
\end{tabular}


Comparative Study Of Intravenous Ondansetron And Intrathecal Fentanyl For Preventi...

\begin{tabular}{|l|l|l|l|l|l|}
\hline \multirow{3}{*}{$\begin{array}{l}\text { POST- } \\
\text { OPERATIVE }\end{array}$} & No=67(95.72\%) & No=68(97.14\%) & & \\
\cline { 2 - 5 } & Nausea & Yes=5(7.15\%) & Yes=2(2.86\%) & 1.35 & $0.25(\mathrm{NS})$ \\
\cline { 2 - 6 } & \multirow{2}{*}{ Retching } & Yes=3(92.85\%) & No=68(97.14\%) & & $0.65(\mathrm{NS})$ \\
& & $\mathrm{No}=67(95.72 \%)$ & $\mathrm{Nos}=68(2.86 \%)$ & 0.21 & \\
\hline
\end{tabular}

NS= Not significant

The IT fentanyl group did not required any rescue analgesic intraoperatively as compared with the Group O and the difference is not significant statistically; this might account for the possibility of intraoperative nausea being correlated with perioperative treatment with IV fentanyl. The rescue analgesic consumption was more in the fentanyl group during the 24 hour postoperative period, eventhough the result was not significant as compared with the ondansetron group. No patients required treatment for pruritus, and all patients maintained adequate oxygenation (Spo2@>97\%) with face mask oxygenation

\section{Discussion}

Nausea and vomiting commonly occurs during caesarean delivery performed with regional anaesthesia and is frequently related to peritoneal traction and exteriorization of the uterus. Stimuli from several areas within the central nervous system can affect the emetic centre. ${ }^{[12]}$ Various prophylactic antiemetics have been used. Metoclopramide, droperidol, and the 5- $\mathrm{HT}_{3}$ antagonists (ondansetron granisetron) are all effective in decreasing intraoperative nausea and vomiting during cesarean delivery. ${ }^{[13]}$ Prophylactic droperidol and ondansetron during caesarean delivery were compared and ondansetron was recommended on the basis of equivalent efficacy and decreased side effects. However, ondansetron, may cause transient headaches and mild elevation of liver enzymes. ${ }^{[17]}$

Intrathecal lipophilic opioids have been studied extensively as adjuvants to spinal anaesthesia for caesarean delivery and may provide improved intra and postoperative analgesia with additional benefit of decreasing intraoperative nausea and vomiting. Dahlgren $\mathrm{G}$ et al ${ }^{[15]}$ studied women undergoing caesarean delivery with either $10 \mu \mathrm{g}$ fentanyl, $2.5 \mu \mathrm{g}$ sufentanil, $5 \mu \mathrm{g}$ sufentanil, or saline placebo added to IT bupivacaine. All of the groups receiving IT lipophilic opioids had significantly less intraoperative nausea and vomiting, with an incidence of $40 \%$. Palmer CM et al ${ }^{16]}$ reported $25 \%$ intraoperative nausea and vomiting in patients who received $15 \mu \mathrm{g}$ fentanyl added to lidocaine spinal anaesthesia. Randalls B et $\mathrm{al}^{[17]}$ and DW Cooper et $\mathrm{al}^{[18]}$ also found a low incidence of nausea and vomiting with IT fentanyl with bupivacaine for caerarean delivery. Ben-David BM et $\mathrm{al}^{[19]}$ found lower incidence of nausea and vomiting in bupivacaine-fentanyl group than the bupivacaine group alone (31\% vs 69\%). Moreover, lower incidences of intraoperative nausea and vomiting were recorded on the studies of Pallab Rudra et al ${ }^{[20]}(15 \%)$ and Kuusniemi KS et al ${ }^{[21]}$ (5\%) using $12.5 \mu$ gm and $25 \mu$ gm of IT fentanyl with bupivacaine respectively. Our study which used $25 \mu \mathrm{gm}$ of IT fentanyl was in agreement with the above studies. The incidence of nausea in our study during the intraoperative peroid was 5(7.15\%) in fentanyl group and $9(12.87 \%)$ in the ondansetron group, vomiting 3(4.28\%) in group fentanyl as compared to 6(8.58\%) in ondansetron; and retching $3(4.28 \%)$ in fentanyl group as compared to $6(8.58 \%)$ in ondansetron group, but no significance was seen statistically.

In the postoperative period, the incidence of nausea was $5(7.15 \%)$ in the fentanyl group and $2(2.86 \%)$ in ondansetron group, vomiting in fentanyl group was 3(4.28\%) where as $2(2.86 \%)$ in ondansetron group and incidence of retching was 3(4.28\%)in fentanyl group and $2(2.86 \%)$ in ondansetron group during post operative period. Statistical analysis showed no significant difference. This insignificant increased incidence of postoperative nausea and vomiting in the fentanyl group was also recorded in the study of Manullang et al. ${ }^{[6]}$

Maternal hypotension occurs commonly with spinal anaesthesia and it is related with the intra operative nausea and vomiting. Hypotension may trigger the vomiting centre and induce nausea and vomiting. In this study, there was fall of systolic pressure at $4^{\text {th }} \mathrm{min}$ in both the group. It was aggressively treated with IV Mephentermine $0.005 \mathrm{mg} / \mathrm{kg}$ and additional $250 \mathrm{ml}$ of Ringer's lactate or colloid. We observed a significant decrease in Mephentermine requirements for the IT fentanyl group compared with the IV ondansetron group. Our findings were similar with that of Ben-David B M et al ${ }^{[19]}$. Bradycardia ( $<60$ beats per min) was not observed in both the groups. The mean values of pulse rate changes and mean arterial pressure (MAP) recorded in both Groups were comparable $(\mathrm{P}>0.05)$. The mean values of mean arterial blood pressure changes in $\mathrm{mmHg}$ between both groups were almost similar. These results were also obtained in the study of Biswas BN et al ${ }^{[22]}$ and Singh $\mathrm{H}$ et al. ${ }^{[23]}$

There was no incidence of any respiratory depression in our study which was in contrast with Singh $\mathrm{H}$ et al, ${ }^{[23]}$ and $\mathrm{Lu} \mathrm{JK}$ et al ${ }^{[24]}$. In all the cases of both the groups, $\mathrm{O} 2$ supplement is given and $\mathrm{SpO} 2$ was maintained above $97 \%$ during both intraoperative and post operative period which was concurrent with the study done by Manullang TR et al ${ }^{[6]}$ These might be explained due to intense monitoring, verbal stimulation, and routine supplemental oxygen that minimized the clinical significance of any mild respiratory depression which occurred.

Pruritus is a known side effect of IT opioids, surprisingly in our study there was no incidence of pruritus in any of the patient in the fentanyl group, and this might probably be due to lower doses of intrathecal fentanyl. ${ }^{[25]}$ Although APGAR scores were similar between the two groups, we acknowledged that this was not a highly sensitive means of neonatal assessment. Umbilical cord blood gas analysis and neonatal neurobehavioral scores might have revealed more subtle effects.

There was no requirement of rescue analgesia in the fentanyl group intraoperatively as also in the study by Manullang TR et al. ${ }^{[6]}$ The 24 hour postoperative period rescue analgesic requirement was more in the fentanyl group as compared with the ondansetron group eventhough not significant. This might be due to the acute spinal tolerance induced by IT fentanyl which demanded increased rescue analgesic.

Our study was not without any limitation. Patients undergoing caesarean delivery under spinal anaesthesia are inherently at high risk for intraoperative nausea and vomiting. Although Intrathecal fentanyl appears superior to IV ondansetron as a single drug to prevent perioperative nausea, it is possible that treatment with multiple drugs with different 
sites of action may benefit certain patient groups. So, combination therapy protocol should be investigated and advocated for the prevention of nausea and vomiting.

\section{Conclusion}

Hence, we concluded that, IT fentanyl $20 \mu \mathrm{gm}$ combined with hyperbaric $0.5 \%$ bupivacaine $12 \mathrm{mg}$ is better option as compared to IV ondansetron $4 \mathrm{mg}$ for spinal anaesthesia in caesarean section deliveries as it would markedly improve intraoperative anaesthesia with good maternal satisfaction and foetal well being.

\section{References}

[1]. Kovac AL. Prevention and treatment of postoperative nausea and vomiting. Drugs 2000; 59: 213-43.

[2]. Watcha MF, White PF. Postoperative nausea and vomiting; its etiology, treatment and prevention. Anaest 1992; 77:162-84

[3]. Eisenach JC, Dewan DM. Metoclopramide exaggerates stress induce tachycardia in pregnancy. Anaest Analg 1996; 83:982-6.

[4]. Pan PH, Moore CH. Intra-operative antiemetic efficacy of prophylactic Ondansetron and Droperidol for caesarean section patient under epidural anaesthesia. Anaest Analg 1996; 83:982-6.

[5]. Fujii Y, Tanaka H, Toyooka H. Granisetron prevent nausea and vomiting during caesarean section under spinal anaesthesia. Acta Anaesthesiology Scand 1998; 42:312-5.

[6]. Manullang TR, Viscomi CM, Pace NL. Intrathecal fentanyl is superior to intravenous ondansetron for the prevention of perioperative nausea during caesarean delivery with spinal anaesthesia. Anaesth Analg 2000; 90: 1162-66.

[7]. Dahlgren G, Hulstrand C, Jakobosson J, Norman M, Eriksson EW, Martin H. Intrathecal sulfetanil, fentanyl or placebo added to bupivacaine for cesarean delivery. Anesth Analg 1997; 85: 1288-93.

[8]. Siddik-Sayyid SM, Aouad MT, Jalbout MI, Zalaket MI, Berzina CE, Baraka AS. Intrathecal versus intravenous fentanyl for supplementation of subarachnoid block during caesarean delivery. Anesth Analg 1992; 95: 209-13.

[9]. Biswas BN, Rudra A, Nath S. A comparison of intrathecal fentanyl with intravenous ondansetron-dexamethasone combination for prevention of intraoperative and early postoperative emesis following spinal anaesthesia for caesarean section. Indian J Anaesth 2001; 45 : 195-97.

[10]. Kim MH, Lee YM. Intrathecal midazolam increases the analgesic effects of spinal blockade with bupivacaine in patients undergoing haemorrhoidectomy. Br J Anaesth 2001; 86:77-9.

[11]. Sen A, Rudra A. Intrathecal midazolam to prevent nauseavomiting during caesarean delivery with spinal anaesthesia. J Anaesth Clin Pharmacol 2002; 18: $21-25$.

[12]. Watcha MF, White PF.Postoperative nausea and vomiting. Its etiology, treatment, and prevention. Anesthesiology. 1992;77(1):162-84.

[13]. Paxton DL, Mckay CA, Mirakin KR. Prevention of nausea and vomiting after day case gynaecological laparoscopy. Anaesthesia1995; 50: 403-6.

[14]. Pan P H and Moore C H. Intraoperative antiemetic efficacy of prophylactic ondansetron versus droperidol for cesarean section patients under epidural anesthesia. Anasth Analg. 1996; 83(5): 982-86

[15]. Dahlgren G, Hultstrand C, Jakobsson J, Norman M, Eriksson EW and Martin H. Intrathecal sufentanil, fentanyl, or placebo added to bupivacaine for cesarean section. Anasth Analg. 1997;85 (6) 1288-93.

[16]. Palmer CM, Voulgaropoulos D, Alves D. Subarachnoid fentanyl augments lidocaine spinal anesthesia for cesarean delivery. Reg Anesth. 1995;20(5):389-94.

[17]. Randalls B, Broadway JW, Browne DA, Morgan BM. Comparison of four subarachnoid solutions in a needle-through-needle technique for elective caesarean section. Br J Anaesth 1991;66: 314-8

[18]. Cooper DW, Lindsay SL, Ryall DM, Kokri MS, Eldabe SS and Lear GA. Does intrathecal fentanyl produce acute cross-tolerance to i.v. morphine? Br. J. Anaesth. 1997; 78 (3):311-13.

[19]. Ben-David B, Miller G, Gavriel R, Gurevitch A. Low dose bupivacaine fentanyl spinal anaesthesia for cesarean delivery. Reg Anesth and Pain Med 2000; 25:235-9.

[20]. Rudra P and Rudra A. Comparison of intrathecal fentanyl and midazolam for prevention of nausea and vomiting during caesarean delivery under spinal anaesthesia. Indian J. Anaesth. 2004; 48(6): 461-64

[21]. Kuusniemi KS, Pihlajama "ki KK, Pitka"nen MT, Helenius HY, Kirvela OA. The use of bupivacaine and fentanyl for Spinal anaesthesia for urologic surgery. Anesth Analg 2000;91:1452-6

[22]. Biswas BN, Rudra A, Bose BK, Nath S, Chakrabarty S, Bhattacharjee S. Intrathecal fentanyl with hyperbaric bupivacaine improves analgesia during caesarean delivery and in early postoperative period. Indian J Anaesth 2002; 46(6):469-72.

[23]. Singh H, Yang J, ThorantonT, Gieseeke AH. Intrathecal fentanyl prolongs sensory bupivacaine spinal block. Can J Anaesth 1995; 42(11):987-97

[24]. Lu JK, Schafer PG, Gardner TL, et al. The dose-response pharmacology of intrathecal sufentanil in female volunteers. Anesth Analg 1997;85:372-

[25]. Buvanendran A, Newman ML, McCarthy RJ, Pharm P, Anthony D, Ivankovich et al. Intrathecal bupivacaine reduces pruritus and prolongs duration of fentanyl analgesia during labor: A prospective, randomized controlled trial. Anesth Analg 1998; 87:1309-15 